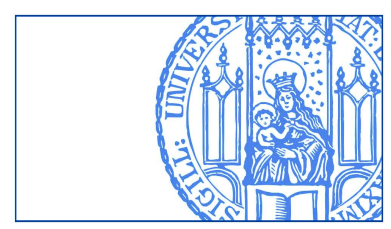

Marin, Dalia und Verdier, Thierry:

Competing in Organizations: Firm Heterogeneity and International Trade

Munich Discussion Paper No. 2007-20

Department of Economics

University of Munich

Volkswirtschaftliche Fakultät

Ludwig-Maximilians-Universitäł München

Online at https://doi.org/10.5282/ubm/epub. 1933 


\title{
Competing in Organizations: Firm Heterogeneity and International Trade *
}

\author{
Dalia Marin, University of Munich \\ Thierry Verdier, Paris School of Economics
}

May 2007

\footnotetext{
*Paper prepared for the Munich CEPR Conference 'Globalization and the Organization of Firms and Markets', February 2007. We thank Elhanan Helpman, Stephen Yeaples and the conference participants for helpful comments. Part of the paper was written when Dalia Marin visited the Stern School of Business of New York University. She thanks for the hospitality and stimulating discussions. Financial support by the Volkswagen Foundation through the network grant 'Globalization and the Organization of Firms and Markets' and by the German Science Foundation through Sonderforschungsbereich GESY SFB/TR 15 and through the research grant DFG-MA-1823/3-1 is gratefully acknowledged.
} 


\begin{abstract}
This paper develops a theory which investigates how firms' choice of corporate organization is affecting firm performance and the nature of competition in international markets. We develop a model in which firms' organisational choices determine heterogeneity across firms in size and productivity in the same industry. We then incorporate these organisational choices in a Krugman cum Melitz and Ottaviano model of international trade. We show that the toughness of competition in a market depends on who - headquarters or middle managers - have power in firms. Furthermore, we propose two new margins of trade adjustments: the monitoring margin and the organizational margin. International trade may or may not lead to an increase in aggregate productivity of an industry depending on which of these margins dominate. Trade may trigger firms to opt for organizations which encourage the creation of new ideas and which are less well adapt to price and cost competition.
\end{abstract}

JEL Classification: F12, F14, L22, D23

Keywords: international trade with endogenous firm organizations and endogenous toughness of competition, firm heterogeneity, power struggle in the firm. 


\section{Introduction}

Until recently international trade theory treated firms as a black box. The firm is characterized by a production function according to which the factors of production (capital, labor) are transformed into consumption goods. Moreover, these firms are assumed to be of equal size and productivity. In reality, however, firms consist of organizations with an inner life and differ in size, productivity, and type of firm organization.

Firm heterogeneity in size and productivity in the same industry are now widely recognized in various empirical firm level studies (Bernard and Jensen 1999, Clerides, Lach and Tybout 1998. A number of recent papers have introduced firm heterogeneity into models of international trade ( Melitz 2003, Bernard, Eaton, Jensen and Kortum 2000, and Melitz and Ottaviano 2005). In all these specifications, the basic ingredients are the same. Firms face an exogenous ex-ante distribution of potential productivity levels. After uncertaincy is realized, entry and competition provide an endogenous mechanism for selection of the equilibrium distribution of productivity within an industry. Trade integration, affecting somewhat the degree of market competition leads to a reallocation to high productivity firms within a sector, with an increase in aggregate productivity providing additional sources of gains from trade for economies. ${ }^{1}$

But what determines differences in productivity and size across firms in the same industry in the first place? Several empirical studies have attempted to clear away productivity differences among firms through better measures of inputs (capital, material, skills) and explicit measures of technology such as Research and Development or Information and Communication Technologies. But an unexplained residual remains. A recent study by Bloom and Van Reenen (2006) attempts to explain these residual differences in firm performance by differences in management practices across firms and countries. Using an elaborate measure of management quality they find that better management practices are significantly associated with higher productivity, profitability, sales growth and firm-survival rates in the four countries US, UK, France, and Germany.

\footnotetext{
${ }^{1}$ For a recent survey, see Bernard et al (2007).
} 

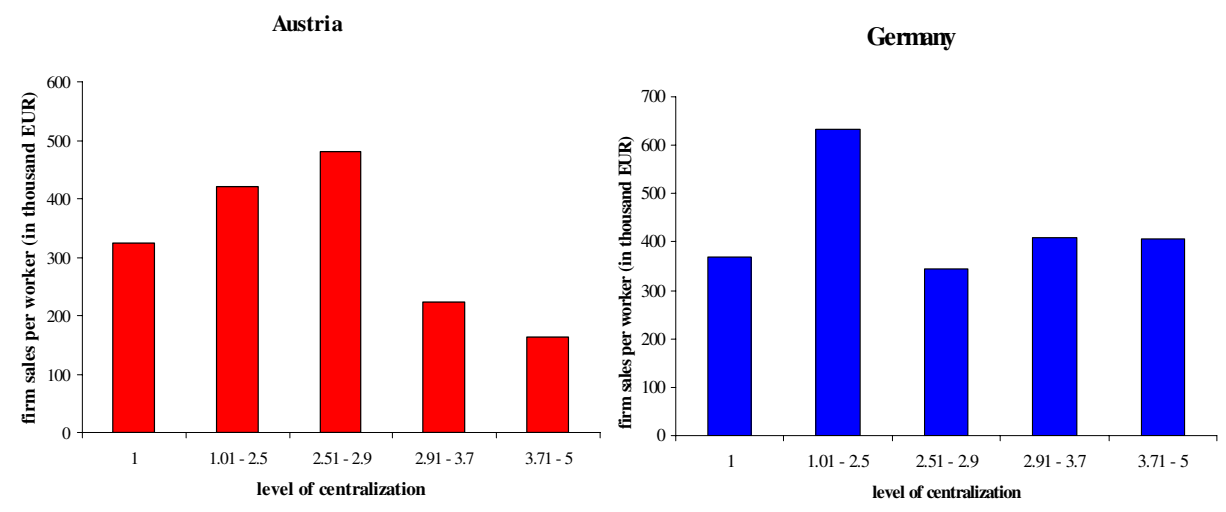

Figure 1: Firm Productivity and Level of Centralization

In this paper we focus on understanding the sources of firms' ex-ante heterogeneity and their implications for competition and international trade. We consider the firms' mode of organization as one natural candidate for the source of firm's productivity heterogeneity. The type of organization may well explain differences in management practices described in Bloom and Van Reenen (2006). We take a first look at the relationship between corporate organization and productivity in Figure 1. The figure plots the pattern between firms' productivity (captured by firms'sales per worker) and the firms' mode of organization. We capture corporate organization by the level of centralization of decision making inside the corporation. Firms are ranked by their level of centralization over several corporate decisions. The numbers in Figure 1 are averages over several corporate decisions ranging between 1 and 5 with 1 as a central decision taken at the CEO level at the top of the organization and 5 as a decentral decision taken at the divisional level. ${ }^{2}$

\footnotetext{
${ }^{2}$ The corporate decisions include the decision over acquisitions, financial decisions, the decision over new strategy, transfer pricing, the decision over a new product, R\&D expenditeures, the decision over the budget, hiring more than 10 percent of current personnel, hiring two workers, change of supplier, price increase of product, decision over product price, moderate wage increase, firing of personnel, the decision of hiring a secretary. For a ranking of these decisions and the description of the data, see Marin and Verdier (2006) and Marin (2006).
} 
The pattern appears to be inverted U-shaped with the most productive firms having a management style in which both headquarters as well as middle managers are involved in the decision making inside the corporation. ${ }^{3}$ This pattern raises the question - what forces explain the relationship between the observed diversity in corporate organization on the one hand and the pattern of heterogeneity among firms in productivity on the other? More specifically, do firms differ in terms of size and productivity because they adopt different types of organizations? Or is the reverse the case that firms have different organizations because they differ in size and productivity?

In earlier work (Marin and Verdier $(2003,2006)$ ) we investigate the second link by focusing on how factor endowments on the one hand and international competition on the other are affecting firm size and the mode of organization firms choose. We find that firms that are neither too skill intensive nor too labour intensive will choose firm organizations in which power is delegated to the divisional level to keep middle managers' initiative alife. We also find that larger more profitable firms will delegate decision control to empower their middle managers. In this paper we are reversing the question by asking how firms' organizational choices determine heterogeneity across firms in size and productivity in the same industry. We develop a model in which firms' choice of corporate organization is affecting firm performance and the nature of competition in international markets. We introduce organizational choices in a Krugman cum Melitz and Ottaviano model of international trade. Our model simultaneously determines firms' organizational choices and heterogeneity across firms in size and productivity. More precisely, we combine within industry heterogeneity of Melitz (2003) and Melitz and Ottaviano (2003) with power in the firm of Marin and Verdier (2006 and 2007). This allows us to study the impact of corporate organization on firm productivity and on the nature of competition in international markets. Moreoever, it allows us to analyse the impact of international trade on aggregate productivity in an industry.

\footnotetext{
${ }^{3}$ We will later define an organization in which headquarters as well as the division level make decisions (level of centralization of around 3) as a P-organization. In terms of the model this is an organization in which the principal runs the firm with the cooperation of the agent. We define an organization to be centrally organized as an O-organization (level of centralization of around 1) which is a single managed firm run by the principal alone. Finally, we define an organization to be decentrally organized as an A-organization run by the divisional manager (level of centralization of around 5).
} 
The paper contributes in several respects to this literature. Antras and Helpman (2004) ask how an exogenous distribution of productivity among firms determine organizational choices on sourcing. Melitz (2003) introduces firm productivity heterogeneity into a Krugman model of trade under monopolistic competition by an exogenous equilibrium distribution of productivity. We endogenize firm heterogeneity in a Krugman model by firms' choice of organization. Our model generates an endogenous 'mix' of firms with different productivity and size levels which is driven by their organizational choices.

Our model predicts intra-firm reallocations from high cost to low cost firms resulting in an increase in average productivity of an industry following episodes of trade liberalizations similar to Melitz (2003). However, the mechanism by which this occurs is entirely different. Rather than through the exit of the least productive firms, trade liberalization increases average productivity by inducing CEOs/owners in firms to monitor more leading to a larger fraction of firms in which CEOs have 'real power' in firms and in which they choose the cost minimizing project. Hence, the productivity effect arises inside firms rather than through reallocation between firms.

However, in contrast to Melitz (2003), a trade shock may or may not increase average productivity depending on the corporate equilibrium that emerges in the economy. Interestingly, we find that the toughness of competition in the market becomes endogenous and depends on who - headquarters or middle managers - have power inside firms. A large enough trade shock may lower productivity in the liberalizing country by inducing a change in corporate equilibrium from a $\mathrm{P}$-organization to an A-organization in which power is delegated to middle managers to promote their incentives to find new projects for the firm. In this case, the shift in the organizational equilibrium towards management empowerment reduces the thoughness of competition with larger mark-ups and equilibrium profits. Aggregate productivity declines for two reasons. First, because principals monitor less leading to a smaller fraction of firms in which principals/owners have 'real power' in firms. Second, because competition becomes less intense helping a larger share of high cost firms survive in the market. Hence, in an empowerment equilibrium which promotes the creation of ideas for new projects competition takes place in quality (more varieties) rather than in price. This way the paper adds two new internal margins of trade adjustment - the monitoring margin and the organizational margin - to the external margin proposed by 
Melitz. $^{4}$

The paper is organized in the following sections. Section 2 presents the basic model of monopolistic competition in a closed economy. Section 3 determines the optimal mode of firm organization. Section 4 incorporates the model of firm organization into the framework of monopolistic competition described in section 2. Section 5 determines the industry equlibrium with free entry. Section 6 shows how the choice of organization determines heterogeneity of firms in terms of size and productivity in the same industry. The section shows also how the nature of competition in international markets depends on the corporate equilibrium that emerges in the economy. The section then determines the productivity dispersion in the different organizational equilibria. Section 7 examines how a trade shock affects aggregate productivity. Section 8 concludes.

\section{The closed economy}

\subsection{Demand side}

Consider an economy with $L$ consumers. Consumer preferences are defined over a continuum of differentiated varieties indexed by $i \in \Omega$ and an homogenous good chosen as the numeraire as in Melitz and Ottaviano (2003). They are given by

$$
U=q_{0}+\beta \int_{i \in \Omega} q_{i} d i-\frac{1}{2} \gamma \int_{i \in \Omega} q_{i}^{2} d i-\frac{1}{2} \eta\left[\int_{i \in \Omega} q_{i} d i\right]^{2}
$$

where $q_{0}$ and $q_{i}$ are respectively consumption of the numeraire good and consumption of variety $i$ of the differentiated sector. The demand parameters $\beta, \gamma$ and $\eta$ are positive with $\beta$ and $\eta$ giving the substitution between the differentiated varieties and the numeraire and the parameter $\gamma$ as the degree of product differentiation between the varieties. Let $p_{i}$ be the price of variety $i$. We assume that consumers have positive demands for the numeraire

\footnotetext{
${ }^{4}$ Bustos (2005) finds evidence for another internal margin - the innovation margin of trade adjustment - to be present in Argentina. Chen, Imbs, Scott (2006) find positive productivity effects in the short run but not in the long run from trade liberalizations in industrialized countries.
} 
good. Then standard utility maximization gives the individual inverse demand function :

$$
p_{i}=\beta-\gamma q_{i}-\eta Q^{c}
$$

where $Q^{c}$ is total consumption level over all varieties:

$$
Q^{c}=\int_{i \in \Omega} q_{i} d i
$$

Noting $N$ the measure of the set of varieties $\Omega$ with positive demands and $\bar{p}$ the average price index

$$
\bar{p}=\frac{1}{N} \int_{i \in \Omega} p_{i} d i
$$

it follows that

$$
\bar{p}=\beta-\frac{\gamma}{N} Q^{c}-\eta Q^{c}=\beta-\frac{\gamma+N \eta}{N} Q^{c}
$$

Hence, the market demand $q_{i}$ for variety $i$ is given by $^{5}$ :

$$
q_{i}=L q_{i}=\frac{\beta L}{\gamma+N \eta}-\frac{L}{\gamma} p_{i}+\frac{N \eta}{\gamma+N \eta} \frac{L}{\gamma} \bar{p}
$$

Note that in this linear demand system for varieties, the price elasticity of demand is now also driven by the 'toughness' of competition in the market induced either by a lower average price for varieties $\bar{p}$ or more product varieties $N$. The price elasticity of demand increases with lower $\bar{p}$ and larger $N{ }^{6}$

\subsubsection{Production}

The numeraire good 0 is produced with constant returns to scale (one unit of good 0 requires one unit of labor) and under perfect competitive conditions.

\footnotetext{
${ }^{5}$ Expression in (1) is valid whenever $q_{i}>0$ which will be the case when

$$
p_{i} \leq \frac{1}{\gamma+\eta N}(\gamma \beta+\eta N \bar{p})
$$
}

${ }^{6}$ For details see Melitz and Ottaviano (2005). 
Each variety of the differentiated good is produced under monopolistically competitive conditions. Suppose that a given variety $i$ is produced with marginal cost $c_{i}$, then profits for that variety can be written as

$$
\pi_{i}=q_{i}\left(p_{i}-c_{i}\right)
$$

The profit maximizing output level $q_{i}=q\left(c_{i}\right)$ and price level $p_{i}=p\left(c_{i}\right)$ are related to each other by:

$$
q_{i}=q\left(c_{i}\right)=\frac{L}{\gamma}\left[p\left(c_{i}\right)-c_{i}\right]
$$

The profit maximizing price can be written as

$$
p\left(c_{i}\right)=\frac{1}{2}\left[c_{i}+\frac{\beta \gamma}{\gamma+N \eta}+\frac{N \eta}{\gamma+N \eta} \bar{p}\right]
$$

with the (absolute) markup over price as

$$
m\left(c_{i}\right)=p\left(c_{i}\right)-c_{i}=\frac{1}{2}\left[\frac{\beta \gamma}{\gamma+N \eta}+\frac{N \eta}{\gamma+N \eta} \bar{p}-c_{i}\right]
$$

The average price $\bar{p}$ and average cost of firms $\bar{c}$ can be expressed as

$$
\begin{gathered}
\bar{p}=\frac{\bar{c}+\frac{\beta \gamma}{\gamma+N \eta}}{\frac{2 \gamma+N \eta}{\gamma+N \eta}} \\
\bar{c}=\frac{1}{N} \int_{i \in \Omega} c_{i} d i
\end{gathered}
$$

and equilibrium profits of a firm with $\operatorname{cost} c_{i}$ are given by

$$
\pi\left(c_{i}\right)=\frac{L}{4 \gamma}\left[c_{D}-c_{i}\right]^{2}
$$

where $c_{D}$ is the the cutoff cost level :

$$
c_{D}=\frac{2 \beta \gamma}{2 \gamma+N \eta}+\frac{N \eta}{2 \gamma+N \eta} \bar{c}
$$

reflecting the cost level of a firm which is just indifferent about leaving or remaining in the industry and earns zero profits. Firms with cost $c_{i}<c_{D}$ earn positive profits. The cut-off cost level $c_{D}$ captures the 'toughness' of competition in an industry. It declines when competition is tougher with more firms around ( larger $N$ ), with more low cost firms in the market (lower average costs $\bar{c}$ ), and when varieties are closer substitutes (smaller $\gamma$ ). ${ }^{7}$

\footnotetext{
${ }^{7}$ see Melitz and Ottaviano (2005) for more details.
} 


\section{Power in the Firm}

In this section we examine how firms decide over the mode of organization. We consider a firm with a simple hierarchy consisting of a CEO (the principal P) hiring a division manager (the agent $\mathrm{A}$ ) to implement a production project. There are $m$ potential and a priori identical projects (or ways to produce a good). Payoffs are ex ante unknown to both parties. Among the $m$ projects, there is one which yields the highest possible benefit $B$ for the principal and one which yields the highest possible benefit $b$ for the agent. Let $\alpha B$ be the principal's expected benefit when the agent's preferred project is implemented with $(0 \leq \alpha \leq 1)$. Assume, for simplicity, that the agent's expected benefit when the principal's preferred project is implemented is 0 . The lower $\alpha$, the larger the conflict of interest between the principal and her agent. Hence, $\alpha$ is a parameter which captures the power struggle in the firm.

$B$ and $b$ are supposed to be known ex ante though the parties do not know ex ante which project yields such payoff. We assume also that, among the $m$ projects, there are some with very high negative payoffs to both parties, implying that choosing randomly a project without being informed is not profitable to both agents who instead prefer to do nothing (project 0 ). This aspect, together with the fact that each uninformed party prefers to rubberstamp the other informed's party suggestion to do nothing, implies that private information about payoffs gives decision control to the informed party. In this case, the informed party has "real power" rather than "formal power" in the firm. Thus, there are two sources of power in the firm, because it is allocated to the manager "formal authority" which is ex-ante contractible, or because the manager is better informed, "real authority". ${ }^{8}$

Parties may acquire information on the payoff structure in the following way. By spending some resource cost :

$$
g_{P}(E)=g \frac{E^{2}}{2}
$$

the principal $P$ learns the payoff structure of all projects with probability $E$ and remains uniformed with probability $1-E$. Similarly, by exerting some

\footnotetext{
${ }^{8}$ As emphasized by Aghion and Tirole (1997), the amount of information acquisition is at the heart of the distinction between "formal" and "real" decision power in firms.
} 
effort :

$$
g_{A}(e)=k e \text { with } e \in[0, \bar{e}], k<b
$$

the agent learns the payoff structure of all projects with probability $e$ and remains uninformed with probability $1-e$.

We assume that the principal is risk neutral and that the agent is infinitely risk averse with respect to income. Therefore, the agent is not responsive to monetary incentives and he agrees to receive a fixed wage $w$ equal to his opportunity cost. His incentives to gather information on projects will be directly related to the private non pecuniary benefit $b$ he gets from his "best" project.

Firms can choose between three types of organizations, a P-organization in which the $\mathrm{CEO} /$ owner has formal power, an A-organization in which the $\mathrm{CEO} /$ owner delegates formal power to the agent, and an O-organization in which the principal has formal power and in which the agent excerts minimum effort. The O-organization can be thought of as a single managed firm (run by the principal) without an internal hierarchy.

Decisions are taken in the following sequence. The principal allocates formal power to herself (P-organization) or to the agent (A-organization). Then the two parties collect information about projects' payoff simultaneously. The party who does not have decision power suggests a project (or nothing) to the other party. Finally, the party with power rubber stamps the other party's suggestion or selects an alternative project, or decides to do nothing. Hence, the party with formal authority, whenever informed, picks her preferred project. When she remains uninformed ex post, that party rubber-stamps the suggestion of the other party who, whenever informed, has real authority over the project choice and gets his preferred project implemented. When neither party has information on the payoff structure, no project is undertaken by the firm.

Let us look then at the equilibrium informational efforts of the two parties under each organization. We first compute the Nash equilibria in information collection and the resulting payoffs under each organization. Then we examine which of these organizations yield higher utility to the principal and is preferred by her.

\section{P-organization}


We start with the case where the principal has formal power in the firm and the agent participates actively in the management of the firm (ie. $e>0$ ). When the principal has formal power, the expected payoffs $u_{P}(E, e)$ for the principal and $\nu_{P}(E, e)$ for the agent are given by:

$$
\begin{aligned}
& U_{P}(E, e)=E B+(1-E) e \alpha B-g_{P}(E)-w \\
& \nu_{P}(E, e)=(1-E) e b-g_{A}(e)
\end{aligned}
$$

With probability $E$, the principal becomes fully informed about her payoffs and picks her preferred project with monetary payoff $B$, while the agent receives 0 . With probability $1-E$, the principal remains uninformed about payoffs. The agent may then learn with probability $e$ the pay-off structure and suggest his best project to the principal (who accepts it). The principal receives a monetary payoff $\alpha B$ while the agent gets his best private benefit $b$. Or the agent may remain also uninformed in which case, no project is undertaken.

The first order conditions of the two parties with respect to efforts $E$ and $e$ are

$$
\text { Principal: } B(1-e \alpha)=g E \text { and Agent: } \begin{array}{r}
e=\bar{e} \text { if } k \leq b(1-E) \\
=0 \text { if } k>b(1-E)
\end{array}
$$

The conditions highlight the trade-off between the principal's control and the agent's initiative. The principal supervises more the higher her stake in the project (the larger $B$ ), the larger the conflict of interest between the principal and the agent (the lower $\alpha$ ) and the lower the agent's effort $e$. The agent, in turn, has more initiative the higher her stake (the larger $b$ ) and the lower the principal's interference (the lower $E$ ). Thus, control comes with the cost of loosing the agent's initiative.

The Nash equilibrium level of efforts of this game are given by

$$
\begin{array}{ll}
e_{P}^{*}=\bar{e}, \text { and } E_{P}^{*}=\frac{B(1-\bar{e} \alpha)}{g} & \text { when } B \leq \widetilde{B}_{P}(\alpha) \\
e_{P}^{*}=0, \text { and } E_{P}^{*}=\frac{B}{g} & \text { when } B>\widetilde{B}_{P}(\alpha)
\end{array}
$$


with

$$
\widetilde{B}_{P}(\alpha)=\frac{g(1-k / b)}{1-\bar{e} \alpha}
$$

$\widetilde{B}_{P}(\alpha)$ captures the threshold level of profits at which the agent's initiative is fully crowded out when the principal has formal power. For payoffs over $\widetilde{B}_{P}(\alpha)$, the principal exerts an effort $E_{P}^{*}$ that kills the initiative of the agent to acquire information. A P-orgarnization with active participation of the agent prevails therefore only when $B<\widetilde{B}_{P}(\alpha)$ The equilibrium expected utility of the principal under this organization is then:

$$
u_{P}(B)=U_{P}\left(\frac{B(1-\bar{e} \alpha)}{g}, \bar{e}\right)
$$

or after substituting (10)

$$
u_{P}(B)=\frac{B^{2}(1-\alpha \bar{e})^{2}}{2 g}+\bar{e} \alpha B-w
$$

\section{O-organization}

Alternatively, whenever profits are sufficiently large $\left(\left(\right.\right.$ ie. $\left.B>\widetilde{B}_{P}(\alpha)\right)$, (10) implies that the agent does not actively engage in the firm (ie. $e=0$ ) in an organizazion with formal power in the hands of the principal. We denote such an organization as an "O-organization". In this case, after substituting (10), the equilibrium expected utility of the principal is

$$
u_{O}(B)=U_{P}\left(\frac{B}{g}, 0\right)=\frac{B^{2}}{2 g}-w
$$

\section{A-organization}

Consider now the case when the principal delegates decision control to the agent and the agent has formal power in the firm. Now the principal is prevented from overruling the agent's decision when both have acquired information. The two parties' expected payoffs are then

$$
\begin{aligned}
U_{A}(E, e) & =e \alpha B+(1-e) E B-g_{P}(E)-w \\
v_{A}(E, e) & =e b-g_{A}(e)
\end{aligned}
$$


Now the agent chooses his preferred project when informed. When the principal is informed and the agent is uninformed, the principal suggests her preferred project, which is then implemented by the agent. For $b>k$, the Nash equilibrium effort levels are ${ }^{9}$

$$
e_{A}^{*}=\bar{e} \text { and } E_{A}^{*}=\frac{B(1-\bar{e})}{g}
$$

A comparison of the effort levels reveals that the agent' $\mathrm{s}$ initiative is better promoted under the A-organization compared to the P-organization. Actually under our specification, the agent will always provide maximum effort under the A-organization while his initiative will be killed under the P-organization for suffieicntly large profits of the principal.

After substituting (13), the equilibrium expected utility of the principal under the A-organization is

$$
u_{A}(B)=U_{A}\left(\frac{B(1-\bar{e})}{g}, \bar{e}\right)=\frac{B^{2}(1-\bar{e})^{2}}{2 g}+\bar{e} \alpha B-w
$$

\section{The Optimal Firm Organization}

We turn now to determine the optimal firm organization. We ask how the parties' informational efforts respond to exogenous changes in the payoff $\mathrm{B}$ and in the conflict parameter $\alpha$ under each organization. We will endogenous B and $\alpha$ by product market competition in the next section. We illustrate the trade-offs the firm faces in its organizational choice with the help of Figure 2 .

\footnotetext{
${ }^{9}$ When the agent receives a strictly positive benefit $\beta b>0$ with the principal's preferred project, there exists as well a threshold $\widetilde{B}_{A}$ given by:

$$
\widetilde{B}_{A}=\frac{g(1-k / b)}{\beta(1-\bar{e})}
$$

and such that the agent's initiative is killed under the A-organization when $B>\widetilde{B}_{A}$. Intuitively, above the threshold level $\widetilde{B}_{A}$ the principal's stakes are so high that she acquires information $E_{A}^{*}$ leading to a high probability of intervention which, in equilibrium, leads again to minimum agent's effort $e_{A}^{*}=0$.
} 


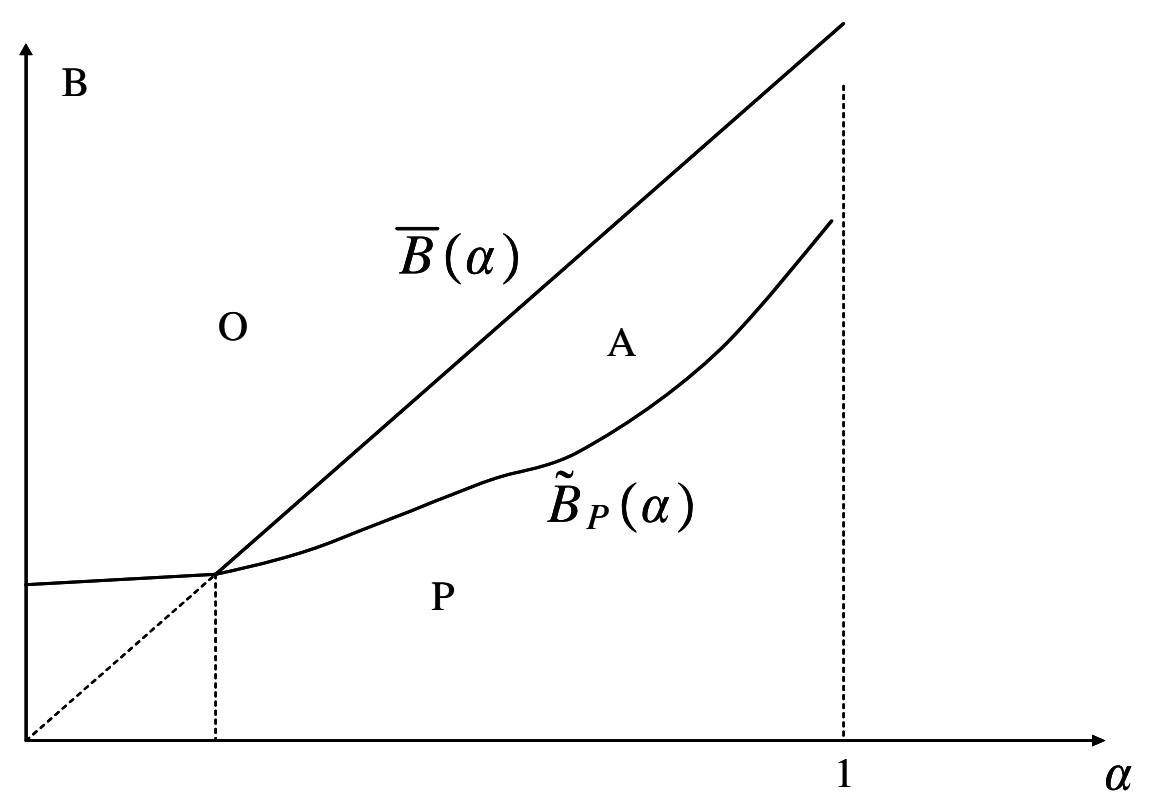

Figure 2: The Optimal Organization of the Firm

The $\tilde{B}_{P}(\alpha)$ - curve relates the profit level to the incentives inside the firm and thus to the costs of having control in the firm. Recall that the $\tilde{B}_{P}(\alpha)$ curve represents the threshold level of profits at which the effort incentive of the agent is killed under the P-organization. $\tilde{B}_{P}(\alpha)$ is upward sloping in $\alpha$ because with an increase in $\alpha$ the conflict of interest between the principal and the agent declines (the preferences between the principal and the agent become more similar). At a given profit level $B$, the principal intervenes less when the agent's preferred project is less in conflict with her objectives. Therefore, the profit level at which the agent's initiative is crowded out goes up. In the area below the $\tilde{B}_{P}(\alpha)$-line the P-firm keeps the agent's initiative alive, while in the area above $\tilde{B}_{P}(\alpha)$ the agent does not exert any effort under the O-organization.

The $\bar{B}(\alpha)$ - line relates the profit level to the market environment of the firm and thus captures the gain of having control in terms of the firms'profits.It is defined by $\bar{B}(\alpha)=\frac{2 g \alpha}{2-\bar{e}}$ as the threshold level of profits at which the principal is indifferent between the O-firm with $e=0$ and the A-firm with the 
agents maximum initiative $\bar{e}^{10} \cdot \bar{B}(\alpha)$ is upward sloping in $\alpha$ because with an increase in $\alpha$ the conflict declines making delegating power to the agent less costly to the principal. Therefore, the level of profits at which the principal is indifferent between the P-firm and the A-firm goes up.

For profit levels below the $\tilde{B}_{P}(\alpha)$-curve the benefit of control outweights the costs and the firm chooses the P-organization. In fact, at low levels of profits there is no trade-off between control and initiative, since the agent's inititative can be kept alive under the P-organization. At low profit levels the principal monitors and intervenes little because her stakes are small and she cares little. Hence, the P-organization gives sufficient initiative to the agent. For profit levels in between the $\tilde{B}_{P}(\alpha)$ - and the $\bar{B}(\alpha)$ - curve, the cost of control outweights the benefit and the firm opts for the A-organization. There is a trade-off between control and initiative and the principal delegates formal power to the agent to keep his initiative and the A-organization emerges as the optimal mode of organization. For profit levels above the $\bar{B}(\alpha)$ - curve, the benefit of control again outweights the costs and the firm chooses the O-organization and looses the initiative of the agent. At high profit levels, there is again no trade-off between control and initiativ. The principal's stakes are so large that she intervenes even under the A-organization leading to minimum effort by the agent even when he is given formal power in the organization. Therefore, the principal might as well keep control by choosing the O-organization. ${ }^{11}$

\section{Competition and the Power Struggle}

We incorporate now the choice of firm organization into the production side described in section 2. We endogenize profits $B$ and the power struggle in firms $\alpha$ in this section. Recall the distinction between formal and real power in the firm. There are two types of firms depending on who - the principal or the agent - has real (as opposed to formal) power in the organization More precisely, assume that firms in which the principals' preferred project is implemented produce the good with production cost $c_{i}=c_{B}$. Call these

\footnotetext{
${ }^{10}$ This is the relevant comparison because the principal always prefers the P-firm with $\bar{e}$ compared to the A-firm with $\bar{e}$.

${ }^{11}$ For a formal proof see Proposition 1 in Marin and Verdier (2006).
} 
firms "real P-firms". Similarly firms in which the agent's preferred project is implemented produce the good with larger production cost $c_{i}=c_{b}=\varphi c_{B}$ and $\varphi>1$. Call these firms "real A-firms". The idea here is that the agent does not always choose the cost minimizing project but rather one that is best for him and maximizes his perks. Thus, even in a 'formal P-firm' in which the principal keeps formal control, the agent's preferred high cost project may get implemented. This will happen when the principal decides not to get informed and to rubber stamp the agent's suggestion. We then have ex-post a 'real A-firm' in a formal P-organization.

From (7) we can then rewrite the principal's profits when her best project is implemented as

$$
B=\pi\left(c_{B}\right)=\frac{L}{4 \gamma}\left[c_{D}-c_{B}\right]^{2}=\frac{L c_{B}^{2}}{4 \gamma}\left[\widetilde{c}_{D}-1\right]^{2} \quad \text { with } \quad \widetilde{c}_{D}=\frac{c_{D}}{c_{B}}
$$

$\widetilde{c}_{D}$ is the cost gap between firms with zero profits $c_{D}$ and the low cost P-firms $c_{B}$. The smaller this gap the harder it is to earn positive profits in the market. Thus, $\widetilde{c}_{D}$ reflects the thoughness of competition that a firm faces. Similarly, the conflict parameter $\alpha$ can also be expressed as a function of the cost gap $\widetilde{c}_{D}$

$$
\alpha=\frac{\pi\left(c_{b}\right)}{\pi\left(c_{B}\right)}=\left[\frac{\widetilde{c}_{D}-\varphi}{\widetilde{c}_{D}-1}\right]^{2}
$$

The smaller $\widetilde{c}_{D}$, the tougher is competition in the market and the larger is the conflict of interest between the principal and her agent (the smaller $\alpha$ ). The power struggle in firms becomes more intense with a decline in relative profits between an A-firm $\pi\left(c_{b}\right)$ in which the agent runs the firm and a P-firm $\pi\left(c_{B}\right)$ in which the principal has power in the firm. Relative profits between these two types of firms decline with tougher competition, because high-cost A-firms' revenues go donw by more than revenues of low-cost Pfirms. A-firms try to fight the loss in revenue $\mathrm{s}$ by lowering mark-ups by more than P-firms. Hence, with more intense competition it matters more who runs the firm and delegation of power to the agent becomes more costly to firms.

Low cost "real P-firms" set lower prices $p$, produce larger outputs $q$ and earn higher revenues $r$ and profits $\pi$ than high cost "real A-firms" as can be 
seen from the following expressions

$$
\begin{gathered}
q_{B}=q\left(c_{B}\right)=L c_{B} \frac{\widetilde{c}_{D}-1}{2 \gamma} \quad \text { while } q_{b}=q\left(c_{b}\right)=L c_{B} \frac{\widetilde{c}_{D}-\varphi}{2 \gamma} \\
p_{B}=p\left(c_{B}\right)=c_{B} \frac{\widetilde{c}_{D}+1}{2} \quad \text { while } p_{b}=p\left(c_{b}\right)=c_{B} \frac{\widetilde{c}_{D}+\varphi}{2} \\
r_{B}=r\left(c_{B}\right)=\frac{L c_{B}^{2}}{4 \gamma}\left(\widetilde{c}_{D}^{2}-1\right) \quad \text { while } \quad r_{b}=r\left(c_{b}\right)=\frac{L c_{B}^{2}}{4 \gamma}\left(\widetilde{c}_{D}^{2}-\varphi^{2}\right) \\
\pi_{B}=\pi\left(c_{B}\right)=\frac{L c_{B}^{2}}{4 \gamma}\left[\widetilde{c}_{D}-1\right]^{2} \quad \text { while } \quad \pi_{b}=\pi\left(c_{b}\right)=\frac{L c_{B}^{2}}{4 \gamma}\left[\widetilde{c}_{D}-\varphi\right]^{2}
\end{gathered}
$$

However, low cost "real P-firms" do not pass on all of the cost differential to consumers in the form of lower prices. They also set higher markups than high cost "real A-firms". This can be seen by expressing the markup of "real P-firms" and "real A-firms", respectively as a function of $\widetilde{c}_{D}$

$$
m_{B}=m\left(c_{B}\right)=c_{B} \frac{\widetilde{c}_{D}-1}{2}, \text { and } m_{b}=m\left(c_{b}\right)=c_{B} \frac{\widetilde{c}_{D}-\varphi}{2}
$$

The two relationships (15) and (16) describe how the thoughness of competition, given by the threshold parameter $\widetilde{c}_{D}$, jointly affects profits and the power struggle inside the firm. Eliminating $\widetilde{c}_{D}$, they define a relationship between $B$ and $\alpha$ that has to be satisfied by any firm. From (15) we get

$$
\widetilde{c}_{D}=1+\frac{2}{c_{B}} \sqrt{\frac{\gamma}{L}} \sqrt{B}
$$

and from (16) we have

$$
\widetilde{c}_{D}=\frac{\varphi-\sqrt{\alpha}}{1-\sqrt{\alpha}}
$$

Therefore, the relationship between $B$ and $\alpha$ is given by

$$
B=\widehat{B}(\alpha)=\left[\frac{\varphi-1}{1-\sqrt{\alpha}}\right]^{2} \frac{L}{\gamma} \frac{c_{B}^{2}}{4}
$$




\section{Industry Equilibrium}

In this section we derive the industry equilibrium with free entry for a given choice of firm organization. ${ }^{12}$ The timing of events is as follows. In a first stage, firms decide whether or not to enter the market and to hire an agent to monitor projects. At this stage, there is free entry. In a second stage, firms decide who has formal power in the organization by choosing between the formal P-firm and the formal A-firm. In a third stage, information collection efforts are realized by the two parties and a project is selected. This, in turn, determines who has real power in the organization. Finally there is production and consumption.

The free entry conditions for a given choice of firm organization can be written as $\operatorname{Max}\left\{u_{P}(B), u_{A}(B), u_{O}(B)\right\}=0$ where $u_{P}(B), u_{A}(B)$, and $u_{O}(B)$ are the profit levels of the firm under each organization $P, A$ or $O$ as given, by (11), (14) and (12) respectively. The "Max" argument in the free entry conditions reflects the fact that each firm decides about its optimal type after market entry. We normalize $w=1$. Three types of free entry equilibria are possible:

i) Equilibrium with P-organization and $e_{P}^{*}=\bar{e}$

The free entry condition in such a regime is

$$
u_{P}(B)=g \frac{\left(E_{P}^{*}\right)^{2}}{2}+\bar{e} \alpha B-1=0
$$

This gives a unique positive solution $B_{P}=B_{P}^{*}(\alpha)$ which is the profit level required to make a firm indifferent between entering and not entering the market as a formal $\mathrm{P}$ organization. Obviously, an equilibrium in this regime exists if and only if $B_{P}^{*}(\alpha) \leq \widetilde{B}_{P}(\alpha)$

ii) Equilibrium with A-organization and $e_{A}^{*}=\bar{e}$.

The free entry condition in such a regime is

$$
u_{A}(B)=g \frac{\left(E_{A}^{*}\right)^{2}}{2}+\bar{e} \alpha B-1=0
$$

\footnotetext{
${ }^{12}$ In Marin and Verdier (2006) we determine the free entry corporate equilibria in which firms choose the profit maximizing mode of organization and in which they have an incentive to enter the market with this organization.
} 
The free entry condition gives similarly a unique positive solution $B_{A}=$ $B_{A}^{*}(\alpha)$. An equilibrium in this regime exists if and only if $\widetilde{B}_{P}(\alpha) \leq B_{A}^{*}(\alpha)<$ $\bar{B}(\alpha)$.

iii) Equilibrium with O-organization and $e_{P}^{*}=0$

Finally the free entry condition in such a regime is

$$
U_{0}(B)=g \frac{\left(E_{0}^{*}\right)^{2}}{2}-1=0
$$

which gives the solution $B_{P}=\sqrt{2 g}$. Such an equilibrium exists when $\sqrt{2 g}>\bar{B}(\alpha)$.

Note that for all values of $\alpha, B_{A}^{*}(\alpha)>B_{P}^{*}(\alpha)$. The formal A-organization, by giving less formal power to the principal, is less efficient than the formal P-organization. Hence, firms require a larger recurrent profit $B$ to enter the market with a formal A-organization compared to a formal P-organization to cover the fixed cost of market entry (ie. the wage rate for the middle manager $w=1) .{ }^{13}$

\section{Firm Heterogeneity}

The model generates ex-post an endogenous pattern of heterogeneity across firms in size and producivity in the same industry. This arises in the following way. Firms choose the type of organization. This choice allocates 'formal' power to principals ( $\mathrm{P}$ - or O-organization) or agents (A-organization). The type of organization, in turn, determines the amount of information collection undertaken by principals and agents which in turn determines the probability of success of finding a project for the firm. It also determines who - headquarters or middle managers - have 'real' power in firms. Firm heterogeneity

\footnotetext{
${ }^{13}$ For more details, see Marin and Verdier (2006). When the cost differential $\varphi-1$ between "high cost" and "low cost" firms is not too large (such that "high cost" firms make positive recurrent profits in a monopolistic equilibrium. with "low cost" firms), we show in Marin and Verdier (2006) that there exists at least one free entry organizational equilibrium $\left(B^{e}, \alpha^{e}\right)$ (defined by the free entry conditions (18), (19) and (20) and the condition (17) on $\widehat{B}(\alpha)$ ) such that a) firms choose optimally their organizations, b) firms maximize profits by choosing the level of production and price and c) there is free entry.
} 
in productivity or costs in an industry arises because even under a 'formal' P-organizational equilibrium in which all firms in an industry adopt an organization in which principals have 'formal' power in the corporation, there will be a share of firms in which agents have 'real' power (real A-firms) when principals in these firms decide not to become informed and to follow the suggestion for projects of their informed middle managers. Principals then implement the high cost projects preferred by middle managers. Similarly, in a formal A-organizational equilibrium in which all firms in an industry delegate 'formal' power to their middle managers, there will be a share of firms in which principals have 'real' power (real P-firms) when middle managers implement low cost projects suggested by informed principals. This way the number of low-cost P-firms and high-cost A-firms in an industry is endogeneous and depends crucially on the organizational equilibrium that emerges in the economy and on the amount of information collection by principals and agents.

\subsubsection{Competition in a P-Equilibrium.}

We turn now to show that the nature of competition in a market becomes endogenous and depends on the corporate equilibrium organization that emerges. Note that by the law of large numbers, given a number of entrants $M$ in the industry, only $N=M[E+(1-E) e]$ of them have information on how to produce in which principals or agents are successfull at collecting information about possible projects for the firm. We can express average costs and cost dispersion in an industry under the P- and A-organizational equilibria ${ }^{14}$ Average marginal costs in an industry $\bar{c}$ become a function of the 'organizational mix'of firms (which is the share of low-cost P-firms and high-cost A-firms in an industry, respectively).

Average Costs and the Thoughness of Competition Consider first the formal P-organizational equilibrium in which firms choose the P-organization

\footnotetext{
${ }^{14}$ Note that in an O-organizational equilibrium, there is no firm heterogeneity. In this equilibrium only projects discovered by the firm/principal are implemented and thus all active firms have the same cost minimizing technology with production $\operatorname{cost} c_{B}$. Therefore, only the organizational equilibria $\mathrm{P}$ and $\mathrm{A}$ have to be examined.
} 
as the optimal mode of organization. Average marginal costs in an industry can then be expressed as

$$
\bar{c}^{P}(E)=\frac{M E}{M[E+(1-E) \bar{e}]} c_{B}+\frac{M(1-E) \bar{e}}{M[E+(1-E) \bar{e}]} c_{b}=\frac{[E+(1-E) \bar{e} \varphi]}{[E+(1-E) \bar{e}]} c_{B}
$$

With probability $E$ the principal gets informed and chooses the project with low $\operatorname{costs} c_{B}$. With probability $(1-E) e$ the principal does not get informed and the agent gets informed in which case he chooses the project with high costs $c_{b}$. Under the law of large numbers, $\frac{E_{P}}{\left[E_{P}+\left(1-E_{P}\right) e\right]}$ and $\frac{\left(1-E_{P}\right) \bar{e}}{\left[E_{P}+\left(1-E_{P}\right) e\right]}$ equal the fraction of low cost 'real P-firms' and high cost 'real A-firms' in the economy. Call these fractions the 'organizational mix' of firms in an industry.

We can then express the thoughness of competition in the market when principals have formal power in firms as the zero profit cut-off cost level

$$
\widetilde{c}_{D}^{P}=\widetilde{c}_{D}^{P}(E, N)=\frac{2 \beta \gamma / c_{B}}{2 \gamma+N \eta}+\frac{N \eta}{2 \gamma+N \eta} \frac{[E+(1-E) \bar{e} \varphi]}{[E+(1-E) \bar{e}]}
$$

with $N=M[E+(1-E) \bar{e}]$, as the "effective" number of varieties produced. ${ }^{15}$ The toughness of competition increases $\left(\widetilde{c}_{D}^{P}\right.$ declines) with the number of varieties $N$ and with the amount of information collection by principals $E$ (with the share of low cost real P-firms). In fact, an increase in $E$ biases the organizational mix between low cost real P-firms and high cost real A-firms in favour of the low-cost P-firms. As a result, average costs in an industry $\bar{c}^{P}(E)$ decline and the thougness of competition in the economy increases.

Cost dispersion The variance of costs in an industry under the P-organization can be expressed as a function of $E$

$$
V_{P}(E)=\frac{E}{[E+(1-E) \bar{e}]}\left[c_{B}-\bar{c}^{P}(E)\right]^{2}+\frac{(1-E) \bar{e}}{[E+(1-E) \bar{e}]}\left[c_{b}-\bar{c}^{P}(E)\right]^{2}
$$

\footnotetext{
${ }^{15}$ When $M$ firms enter not all of them find a profitable project to produce and hence the effective number of successfull firms is $N$.
} 
which can be rewritten to

$$
V_{P}(E)=\frac{E(1-E) \bar{e}[\varphi-1]^{2}}{[E+(1-E) \bar{e}]^{3}} c_{B}^{2}
$$

Differentiating $V_{P}(E)$ reveals that the function is bell shaped. More precisely,

$$
\frac{d V_{P}(E)}{d E} \leq 0 \text { if and only if } E^{2}(1-\bar{e})-2 E+\bar{e} \leq 0
$$

Hence there exists a value $\left.\bar{E}_{P}(\bar{e}) \in\right] 0,1\left[\right.$ such that $V_{P}(E)$ is increasing in $E$ if and only if $E \leq \bar{E}_{P}(\bar{e}) .{ }^{16}$

\subsubsection{Competition in an A-Equilibrium.}

Average Costs and the Thoughness of Competition Similarly, in a formal A-organizational equilibrium in which the A-organization maximizes profits of firms, average marginal costs in an industry are

$$
\bar{c}^{A}(E)=\frac{M \bar{e}}{M[\bar{e}+(1-\bar{e}) E]} c_{b}+\frac{M(1-\bar{e}) E c_{B}}{M[\bar{e}+(1-\bar{e}) E]} c_{B}=\frac{[E+(\varphi-E) \bar{e}]}{[E+(1-E) \bar{e}]} c_{B}
$$

with $\frac{\bar{e}}{\left[E_{A}+\left(1-E_{A}\right) \bar{e}\right]}$ and $\frac{E(1-\bar{e})}{\left[E+\left(1-E_{A}\right) \bar{e}\right]}$ as the fraction of high cost real A-firms and low cost real P-firms in the economy.

The thoughness of competition in the market when principals delegate formal power to middle managers can be expressed as

$$
\widetilde{c}_{D}^{A}=\widetilde{c}_{D}^{A}(E, N)=\frac{2 \beta \gamma / c_{B}}{2 \gamma+N \eta}+\frac{N \eta}{2 \gamma+N \eta} \frac{[E+(\varphi-E) \bar{e}]}{[E+(1-E) \bar{e}]}
$$

Comparing the cut-off cost levels in the two organizational equilibria reveals that $\widetilde{c}_{D}^{P}<\widetilde{c}_{D}^{A}$. Competition is tougher in a P-equilibrium compared to an A-equilibrium as principals monitor more in the former (an increase in $E$ ) which biases the organizational mix in favour of the low-cost P-firms with $\bar{c}^{P}(E)<\bar{c}^{A}(E)$.

\footnotetext{
${ }^{16}$ Formally, $\bar{E}_{P}(\bar{e})$ is the root between 0 and 1 of the equation $E^{2}(1-\bar{e})-2 E+\bar{e}=0$.
} 
Cost dispersion Similarly, in a formal A-organizational equilibrium, the cost dispersion is given by

$$
V_{A}(E)=\frac{(1-\bar{e}) E}{[\bar{e}+(1-\bar{e}) E]}\left[c_{B}-\bar{c}^{A}(E)\right]^{2}+\frac{\bar{e}}{[\bar{e}+(1-\bar{e}) E]}\left[c_{b}-\bar{c}^{A}(E)\right]^{2}
$$

which can be rewritten to

$$
V_{A}(E)=\frac{E \bar{e}(1-\bar{e})[\varphi-1]^{2}}{[E+(1-E) \bar{e}]^{3}} c_{B}^{2}
$$

Differentiating $V_{A}(E)$ shows that the function is bell shaped. More precisely

$$
\frac{d V_{A}(E)}{d E} \leq 0 \text { if and only if } \bar{e}-2(1-\bar{e}) E \leq 0
$$

$V_{A}(E)$ is increasing in $E$ if and only if $E \leq \bar{E}_{A}(\bar{e}){ }^{17}$

Comparing the variances $V_{P}(E)$ and $V_{A}(E)$ in the two organizational equilibria for a given value of $E$ it is clear that for $E \neq 0$,

$$
V_{P}(E) \leq V_{A}(E) \text { if and only if } \bar{e} \leq E
$$

Hence, for the same effort level $E$, the P-organizational equilibrium exhibits less cost dispersion than an A-organizational equilibrium if the firm/principal is more efficient than the agent in collecting information.

The two variance functions are plotted in Figure 3. As can be seen, the cost dispersion under a $\mathrm{P}$-organization is first increasing faster and then decreasing faster with $E$ than that of the A-organization. The intuition for this pattern is as follows. In any organizational regime ( $\mathrm{P}$ or $\mathrm{A})$, a higher effort of information collection $E$ of the firm implies more firms with low costs $c_{B}$. As average costs move away from $c_{b}$ towards $c_{B}$, we have a decrease in the wedge $\left[c_{B}-\bar{c}(E)\right]^{2}$ and conversely an increase in the wedge $\left[c_{b}-\bar{c}(E)\right]^{2}$. Now, in

\footnotetext{
${ }^{17} \bar{E}_{A}(\bar{e})=[\bar{e} / 2(1-\bar{e})]$ and one can show that $\bar{E}_{A}(\bar{e})>\bar{E}_{P}(\bar{e})$ as drawn in Figure 3.
} 


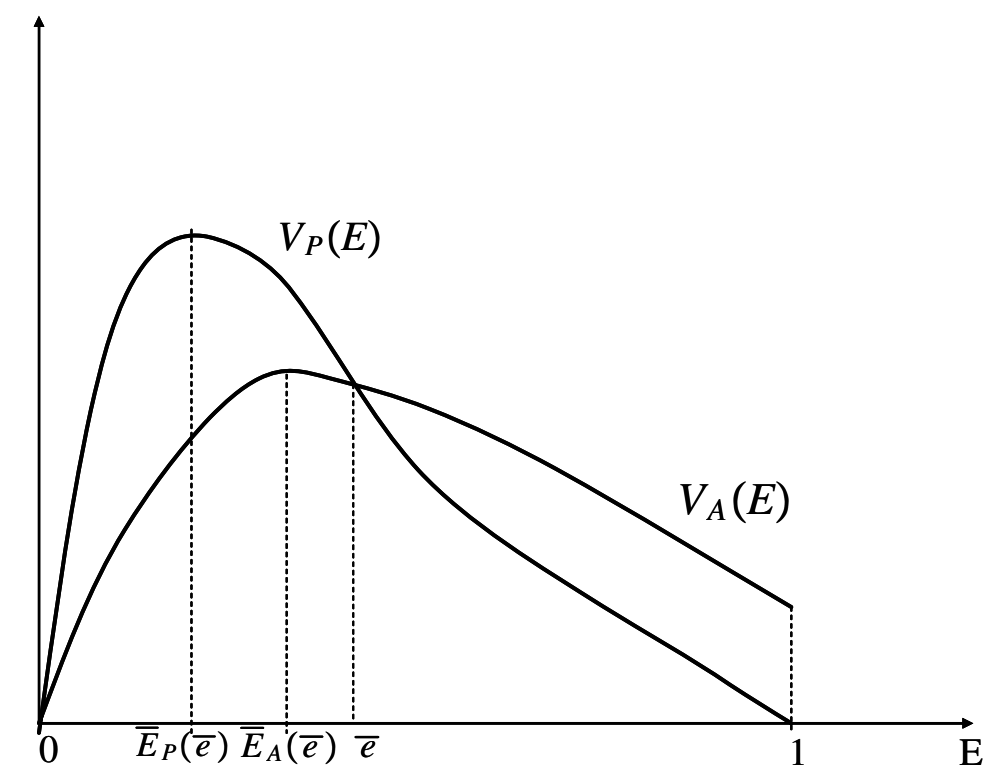

Figure 3: Cost Dispersion in Organizational Equilibria

a P-organizational equilibrium, because the firm has formal power, the fraction of low cost firms (ie. with $c_{B}$ ) is more sensitive to a change in $E$ than in an A-organizational equilibrium. Hence, $\left[c_{B}-\bar{c}(E)\right]^{2}$ and $\left[c_{b}-\bar{c}(E)\right]^{2}$ are more sensitive to a change in the principal's effort $E$ in the P-organization compared to the A-organization. ${ }^{18}$

At low levels of $E$, wedges of type $\left[c_{B}-\bar{c}(E)\right]^{2}$ do not have much weight in the variance terms $V_{P}(E)$ and $V_{A}(E)$. Hence, much of the comparison between $V_{P}(E)$ and $V_{A}(E)$ is driven by the behavior of wegdes $\left|c_{b}-\bar{c}^{P}(E)\right|$ and $\left|c_{b}-\bar{c}^{A}(E)\right|$. It follows that the variance of costs under a P-organizational equilibrium is increasing faster than the same variance under an A-organizational equilibrium. Conversely, when $E$ is close to 1 , variations in $\left[c_{B}-\bar{c}(E)\right]^{2}$ explain much of the shape of the variances $V_{P}(E)$ and $V_{A}(E)$. Thus, at large

\footnotetext{
${ }^{18}$ Formally this can be seen from the following expressions. $\left|c_{B}-\bar{c}^{P}(E)\right|=$ $\frac{(1-E) \bar{e}}{[E+(1-E) \bar{e}]}(\varphi-1) c_{B}$ and $\left|c_{b}-\bar{c}^{P}(E)\right|=\frac{E}{[E+(1-E) \bar{e}]}(\varphi-1) c_{B}$ for the P-equilibrium and $\left|c_{B}-\bar{c}^{A}(E)\right|=\frac{\bar{e}}{[E+(1-E) \bar{e}]}(\varphi-1) c_{B}$ and $\left|c_{b}-\bar{c}^{A}(E)\right|=\frac{E(1-\bar{e})}{[E+(1-E) \bar{e}]}(\varphi-1) c_{B} \quad$ for the A-equilibrium. Indeed, $\left|c_{B}-\bar{c}^{P}(E)\right|$ declines faster with $E$ than $\left|c_{B}-\bar{c}^{A}(E)\right|$, while $\left|c_{b}-\bar{c}^{P}(E)\right|$ increases faster with $E$ than $\left|c_{b}-\bar{c}^{A}(E)\right|$.
} 
values of $E$, the cost dispersion under the P-organzation declines faster with $E$ than under the A-organization.

We are now in a position to examine how trade integration affects the pattern of firm heterogeneity in an industry. We focus on the effect on the first moment of the distribution (ie. average productivity) and discuss two new internal margins of adjustments of trade: the monitoring margin and the organizational margin.

\section{Trade Integration and Aggregate Produc- tivity}

Consider two countries $H$ and $F$ which are identical in all dimensions but market size with $L_{H}>L_{F}$. Assume that there is free trade between $H$ and $F$. Perfect trade integration is equivalent to an increase in market size from $L_{H}$ or $L_{F}$ to $L_{H}+L_{F}$. A change in market size $L$ affects the productivity of the economy via two channels. First, a change in $L$ affects the distribution between high and low cost firms. Second, a change in $L$ affects the optimal pattern of organization. Hence, trade integration triggers a productivity effect within a given organizational equilibrium ( $\mathrm{P}$ or $\mathrm{A})$ and across organizational equilibria when the trade shock induces firms to change their equilibrium organization. We now discuss each effect in turn. ${ }^{19}$

\subsection{The Monitoring Margin of Trade Adjustment}

Consider first a small trade shock. A small increase in market size $L$ increases firms' outputs and profits, inducing firm entry, tougher competition and smaller markups. With increased competition delegation of power inside the firm becomes more costly and tends to increase the power struggle between principals and managers (lower $\alpha$ ). A larger conflict of interest in firms and bigger profits, in turn, stimulate monitoring by principals (increased effort $E$ ), making it more likely that the initiative of the agent is crowded out

\footnotetext{
${ }^{19}$ In Marin and Verdier (2006) we derive the conditions under which a change in $L$ triggers a change in corporate organization.
} 


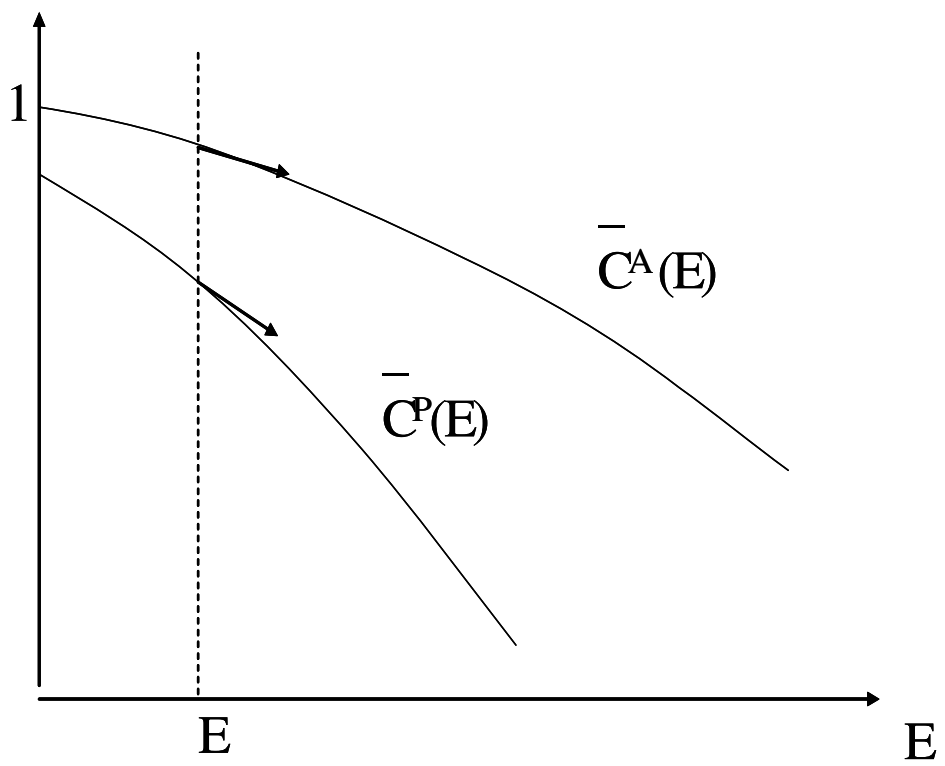

Figure 4: Average Costs in an Industry and Organizational Equilibria

under the central P-organization. When the trade shock is not too large, profits and the power stuggle in firms increase only little and principals monitor only little under the P-organization. Hence, principals' monitoring does not kill the initiative of agents and firms keep the P-organization. As long as the trade shock is not too large no change in corporate organization occurs 20

The effect of a small trade shock on average productivity or equivalently on average costs in an industry is illustrated in Figure 4. The figure plots how average costs in an industry in the two organizational equilibria $\mathrm{P}$ and $\mathrm{A} \bar{c}^{P}(E)$ and $\bar{c}^{A}(E)$ are affected by a change in $E$ (which affects the fraction of low cost real P-firms in the economy). Three things are noteworthy. First, for a given value of $E$, average costs in a P-organizational equilibrium $\bar{c}^{P}(E)$ are always below average costs in an A-organizational equilibrium $\bar{c}^{A}(E)$.

\footnotetext{
${ }^{20}$ For details on the comparative statics of a change in market size, see section 4 in Marin and Verdier (2006).
} 
The reason is simply that the fraction of low cost firms is larger in a Pequilibrium than in an A-equilibrium. Second, both $\bar{c}^{P}(E)$ and $\bar{c}^{A}(E)$ are declining with $E$, as an increase in $E$ is directly related to an increase in the fraction of low cost firms in both regimes. Third, $\bar{c}^{P}(E)$ declines more sharply with an increase in $E$ than $\bar{c}^{A}(E)$ (ie. $\bar{c}^{P}(E)$ is steeper than $\bar{c}^{A}(E)$ ), because the fraction of low cost firms is larger in a P-regime than in an Aregime. Formally, this can be seen from differentiating (21) and (22) with respect to $E$

$$
\frac{d \bar{c}^{P}(E)}{d E}=-\frac{(\varphi-1) e}{[E+(1-E) e]^{2}} c_{B} \text { and } \frac{d \bar{c}^{A}(E)}{d E}=-\frac{(\varphi-1) e(1-e)}{[E+(1-E) e]^{2}} c_{B}
$$

A small trade shock increases equilibrium profits $B$ within an organizational regime. This induces more monitoring $E_{P}$ or $E_{A}$ by principals. As a result the population of active firms is biased towards "real P-firms" at the expense of "real A-firms". This reallocation from high cost firms to low cost firms reduces average production costs in an industry within each organizational regime. Furthermore, a small trade shock increases the conflict of interest between firms and managers in the corporation. As can be seen from (9), within the P-organizational equilibrium the increase in the power struggle in firms also increases monitoring $E_{P}$ by principals, reducing even further average production costs $\bar{c}^{P}(E)$ within this equilibrium. From this discussion we may conclude

Statement 1: A small trade shock increases average productivity by inducing the monitoring margin of trade adjustment. As a result the fraction of low cost P-firms increases at the expense of high cost A-firms. Average productivity increases more in a formal P-organizational equilibrium than in a formal $A$ - organizational equilibrium.

\subsection{The Organizational Margin of Trade Adjustment}

Consider now a large trade shock. When the trade shock is large, profits and the power stuggle in firms become sufficiently large that the stakes rise and principals in firms start to monitor intensively and kill the initiative of agents under the P-organization. To prevent this from happening principals delegate 


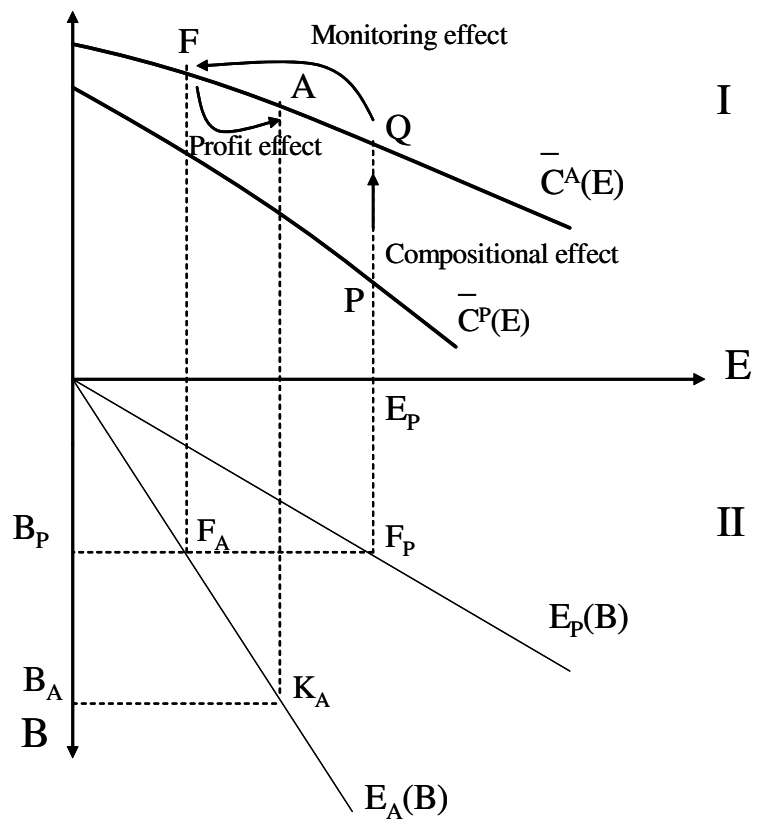

Figure 5: Average Costs in an Industry across Organizational Equilibria

formal power to agents to keep their initiative alife and the A-organization emerges as the new corporate equilibrium ${ }^{21}$

To assess the impact of a change in organization from $\mathrm{P}$ to $\mathrm{A}$ on aggregate productivity, three distinct effects have to be evaluated. They are illustrated in Figure 5. Quadrant I reproduces Figure 4, while quadrant II plots the principal's monitoring under the two organizational equilibria $E_{P}(B)$ and $E_{A}(B)$ as a function of profits $B$.

The first effect is the composition effect between low cost P-firms and high cost $\mathrm{A}$-firms across organizational equilibria $\mathrm{P}$ and $\mathrm{A}$. In fact, for a given value of monitoring $E$ by firms, an A-organizational equilibrium is

\footnotetext{
${ }^{21}$ See Marin and Verdier (2006), section 4 for the conditions under which an increase in market size triggers a shift from the P-organization to the A-organization.
} 
more likely to provide agents with real power in the firm compared to a $\mathrm{P}$ organizational equilibrium. Hence, at a given value of $E$, an A-equilibrium has a larger fraction of high cost "real A-firms" than low costs "real P-firms". This is reflected in quadrant I by the fact that $\bar{c}^{A}(E)$ is always above $\bar{c}^{P}(E)$ for all levels of $E$.

The second effect is the monitoring effect across organizational equilibria $\mathrm{P}$ and $\mathrm{A}$. At a given profit level $B$, a "formal P-firm" monitors more than a "formal A-firm" (ie. $E_{P}(B)>E_{A}(B)$ as can be seen from (9) and (13)). This is illustrated in quadrant II of Figure 11 by the fact that the $E_{P}(B)$ curve is always above the $E_{A}(B)$ curve.

Finally, the last effect is the profit effect. Indeed, given that a formal A-organization is less efficient that a formal $\mathrm{P}$-organization at any value of recurrent profit, it follows that the required profits under free entry in a Aequilibrium $B_{A}=B_{A}^{*}\left(\alpha_{A}\right)$ are larger than the required profit $B_{P}=B_{P}^{*}\left(\alpha_{P}\right)$, in a $\mathrm{P}$-equilibrium. From this it follows that the value of monitoring in formal A-organizations $E_{A}=(1-e) B_{A} / g$ is larger than in formal P-organizations $E_{P}=\left(1-e \alpha_{P}\right) B_{P} / g$. This is illustrated in quadrant II of Figure 5 by the fact that $B_{A}$ is above $B_{P}$ on the vertical axis.

Now we are ready to see how the three effects together influence average costs across organizational equilibria from $\mathrm{P}$ to $\mathrm{A}$. We simply need to compare the values of $\bar{c}^{A}\left(E_{A}\right)$ corresponding to point $A$ with $\bar{c}^{P}\left(E_{P}\right)$ corresponding to point $P$. The composition effect is shown in quadrant I by a vertical move from point $P$ on $\bar{c}^{P}(E)$ to point $Q$ on $\bar{c}^{A}(E)$ for the same value of monitoring $E_{P}$. This effect clearly contributes to an increase in average costs when the corporate equilibrium shifts from a P-organization to an A-organization.

The monitoring effect is illustrated in quadrant II by a horizontal move from point $F_{P}$ with coordinates $\left(E_{P}, B_{P}\right)$ on the curve $E_{P}(B)$ to point $F_{A}$ on the curve $E_{A}(B)$ with coordinates $\left(E_{A}\left(B_{P}\right), B_{P}\right)$. This effect is shown in quadrant I by a move from $Q$ to $F$ along $\bar{c}^{A}(E)$. This effect also increases average costs across organizational equilibria from $\mathrm{P}$ to $\mathrm{A}$.

Finally, the profit effect is illustrated in quadrant II by a move from $F_{A}$ to point $K_{A}$ along the curve $E_{A}(B)$ increasing profits from $B_{P}$ to $B_{A}$. This effect is shown in quadrant I by a move from point $F$ to $A$ along the $\bar{c}^{A}(E)$ curve. The profit effect reduces average costs when the industry shifts from 
a P-organization to an A-organization and thus works in opposite direction to the two other effects. Overall, a trade induced change in organization from $\mathrm{P}$ to $\mathrm{A}$ has an ambiguious effect on productivity and depends on the relative size of each of the three effects. Note that the profit effect has to be strong enough to compensate the first two effects. When the profit effect is not too large $\mathrm{e}^{22}$, it is likely that a shift in corporate organization from a Pequilibrium to an A-equilibrium in response to a large trade shock will lower average productivity in the economy. This discussion can be summarized in the following statement

Statement 2: A large trade shock induces the organizational margin of trade adjustment. The impact of a large trade shock on average productivity can be decomposed into three effects: the composition effect, the monitoring effect, and the profit effect. The composition and monitoring effect both tend to decrease average productivity with an increase in market size $L$ and the profit effect tends to increase average productivity. When the profit effect is not too large, a move from a P-organizational equilibrium to an A-organizational equilibrium is likely to reduce average

Statements 1 and 2 can be finally summarized in Figure 6 which describes the evolution of average costs in the economy as a function of market size $L$. The curve has three parts $\bar{c}^{P}(L), \bar{c}^{A}(L)$ and $\bar{c}^{O}(L)$ depending on the organizational equilibrium $P, A$ or $O$. From statement 1 , we know that average costs are declining within an organizational equilibrium and the curves $\bar{c}^{P}(L)$ and $\bar{c}^{A}(L)$ are declining with market size. In the O-equilibrium the average cost curve becomes $\bar{c}^{O}(L)=c_{B}$, as all active firms are low cost "real

\footnotetext{
${ }^{22}$ Whether the shift in equilibrium profits across organizational equilibria is large or small depends on how efficient the agent is in collecting information. The less efficient the agent is in information collection (ie $e \ll 1$ ), the smaller is the gap between the free entry profit curves $B_{P}^{*}$ and $B_{A}^{*}$ under the two equilibria $P$ and $A$. Intuitively, when the agent is not too efficient at getting information on projects, he is unlikely to have real power in the firm. Hence, it is not too costly to give him formal power in the firm either. In such a case, the shift in equilibrium profits across regimes is small and therefore average costs are likely to increase with a move from a $P$ to an $A$-organizational equilibrium.
} 


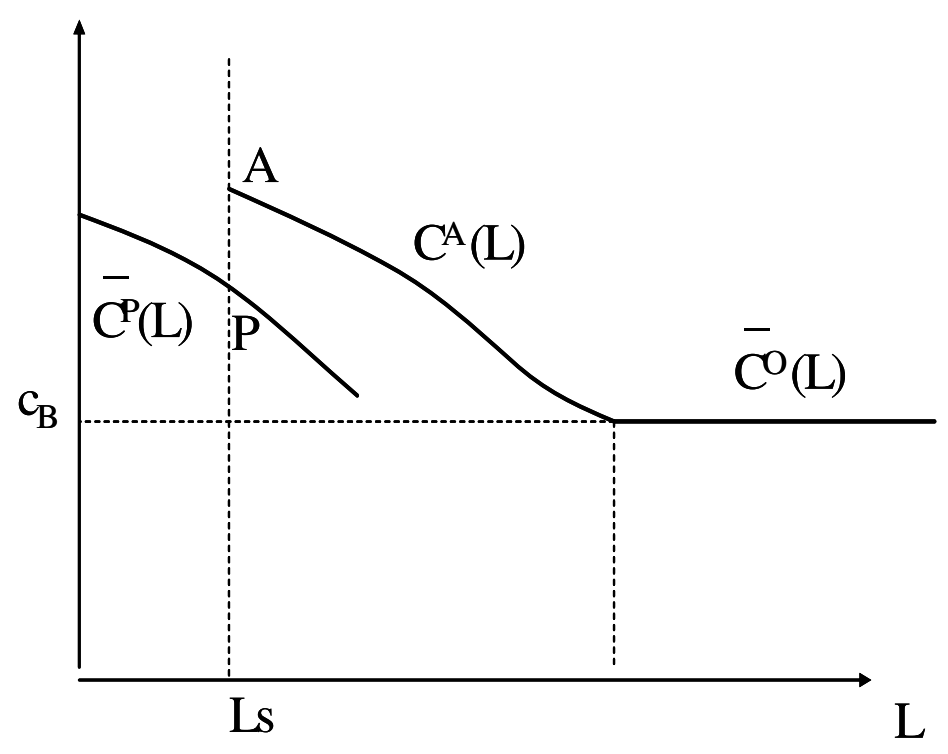

Figure 6: Average Costs in an Industry and Market Size

P- firms". At some threshold value of $L=\widehat{L}$, the A-organization emerges as a new equilibrium and the economy shifts from a P-organization to an A-organization. This shift introduces a discontinuity in average costs. When the profit effect is not too large compared to the other two effects average costs go up (and productivity declines) with an increase in market size as is illustrated in Figure 6. Hence, average costs (or productivity) are not necessarily a decreasing monotonic function of market size, since firms may find it optimal to shift from a low cost organizational equilibrium to a high cost organizational equilibrium with an accompanied increase in average costs in an industry.

As a result, a sufficiently large trade shock may induce an equilibrium in the liberalizing country in which managers are empowered to create ideas for new projects. Average productivity declines at the industry level, since managers will implement projects which maximize their interest. These projects are not necessarily cost minimizing. Furthermore, in the empowerment equilibrium competition becomes less intense and less sensitive to price. Recently, Melitz (2003) has shown that trade integration brings average productivity 
gains through reallocation from high-cost to low-cost firms. Our findings suggest, however, that this will not neccessarily be the case when firms are allowed to choose their organization endogenously. Under some circumstances firms may opt for organizations which are conducive to new ideas and less well adept to price and cost competition.

\section{Conclusions}

This paper develops a theory which investigates how firms' organizational choices are affecting firm performance and the nature of competition in international markets. Firm heterogeneity arises by the type of organization firms choose which, in turn, allocates power to headquarters or middle managers. The power allocation in firms, in turn, determines the amount of information collection that firms undertake. The number of low productivity and high productivity firms in an industry evolves endogenously depending on the corporate equilibrium that emerges in the economy. We find that competition is less intense in markets in which principals delegate power to their middle managers. We also identify two new internal margins of trade adjustment which determine whether or not trade liberalizations lead to productivity gains. 


\section{References}

[1] Aghion, P. and J. Tirole. 1997. Formal and Real Authority in Organizations. Journal of Political Economy. 105 (1). pp. 1-29.

[2] Antras, P. and E. Helpman. 2004. Global Sourcing. Journal of Political Economy 112. pp 552-580.

[3] Bernard, A. and B. Jensen. 1999. Exceptional Exporter Performance: Cause, Effect, or Both? Journal of International Economics 47(1).pp $1-25$.

[4] Bernard, A, J. Eaton, B. Jensen, S. Kortum. 2003. Plants and Productivity in International Trade. American Economic Review 93(4). pp 1268-1290.

[5] Bernard, A.J., B. Jensen, St. Redding, P. Scott. 2007. Firms in International Trade. Journal of Economic Perspectives, forthcoming.

[6] Bloom, N. and J. Van Reenen. 2006. Measuring and Explaining Management Practices across Firms and Countries. Centre for Economic Policy Research. Discussion Paper No. 5581, London.

[7] Bustos, P. 2005. The Impact of Trade on Technology and Skill Upgrading. Evidence from Argentina, CREI, Peompeu Fabra, Mimeo.

[8] Chen, N. J. Imbs, A. Scott. 2006. The Dynamics of Trade and Competition, University of Warwick, HEC Lausanne and London Business School, Mimeo.

[9] Clerides,S. S. Lach, J. Tybout. 1998 Is Learning by Exporting Important? Micro-dynamic Evidence from Columbia, Mexico and Marocco. Quarterly Journal of Economics, 113

[10] Dixit, A. and J. Stiglitz .1977. Monopolistic Competition and Optimum Product Diversity.American Economic Review. 67 (3). pp. 297-308.

[11] Krugman, P. 1979. Increasing Returns, Monopolistic Competition, and International Trade. Journal of International Economics 9, 469-479.

[12] Krugman, P. 1980. Scale Economies, Product Differentiation, and the Pattern of Trade. American Economic Review.70.950-959. 
[13] Marin, D. 2006. A New International Division of Labour in Europe: Outsourcing and Offshoring to Eastern Europe, Journal of the European Economic Association, Papers and Proceedings, May.

[14] Marin, D. and T. Verdier. 2003a. Globalization and the 'New Enterprise'. Journal of the European Economic Association. Papers and Proceedings.

[15] Marin, D. and T. Verdier. 2003b. Globalization and the Empowerment of Talent. CEPR Discussion Paper No. 4129, London.

[16] Marin, D. and T. Verdier. 2006. Corporate Hierarchies and the Size of Nations: Theory and Evidence, University of Munich and Paris School of Economics, Mimeo.

[17] Marin, D. and T. Verdier. 2007. Power Inside the Firm and the Market: A General Equilibrium Approach. Journal of the European Economic Assoication, forthcoming.

[18] Melitz, M. 2003. The Impact of Trade on Aggregate Industry Productivity and Intra-Industry Reallocations. Econometrica 71(6). pp. 16951726.

[19] Melitz, M. and G. Ottaviano. 2005. Market Size, Trade and Productivity. NBER Working Paper No. 11393. 